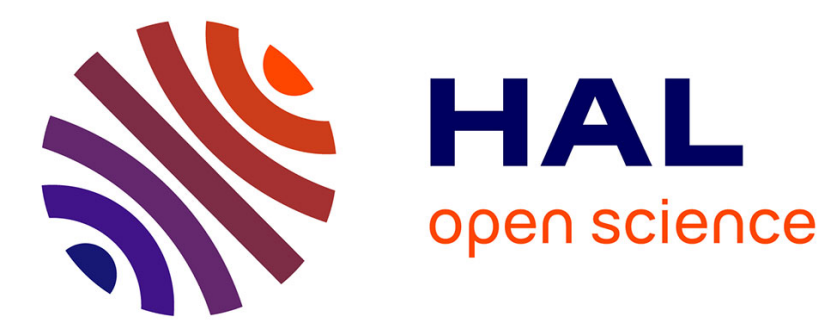

\title{
Seed viability as a function of moisture and temperature in the recalcitrant rainforest species Baccaurea ramiflora (Euphorbiaceae)
}

\author{
Bin Wen, Yifan Cai
}

\section{- To cite this version:}

Bin Wen, Yifan Cai. Seed viability as a function of moisture and temperature in the recalcitrant rainforest species Baccaurea ramiflora (Euphorbiaceae). Annals of Forest Science, 2014, 71 (8), pp.853861. 10.1007/s13595-014-0388-y . hal-01102931

\section{HAL Id: hal-01102931 \\ https://hal.science/hal-01102931}

Submitted on 13 Jan 2015

HAL is a multi-disciplinary open access archive for the deposit and dissemination of scientific research documents, whether they are published or not. The documents may come from teaching and research institutions in France or abroad, or from public or private research centers.
L'archive ouverte pluridisciplinaire HAL, est destinée au dépôt et à la diffusion de documents scientifiques de niveau recherche, publiés ou non, émanant des établissements d'enseignement et de recherche français ou étrangers, des laboratoires publics ou privés. 


\title{
Seed viability as a function of moisture and temperature in the recalcitrant rainforest species Baccaurea ramiflora (Euphorbiaceae)
}

\author{
Bin Wen • Yifan Cai
}

Received: 15 March 2014 / Accepted: 19 May 2014 / Published online: 11 June 2014

(C) INRA and Springer-Verlag France 2014

\begin{abstract}
- Context Fragmentation is a common and increasingly serious problem in tropical rainforests through the world, resulting in changes in species composition and subsequent species extinctions.

- Aim The aim of this study was to test the hypothesis that changes in species composition can originate from the different selection pressures on pioneer and climax seeds as the habitat changes.

- Methods Baccaurea ramiflora seeds were placed on the ground in six quadrats in five different habitats in the field, while graded temperature and relative humidity treatments in the laboratory were used to mimic the changed microclimate in rainforest fragments. Changes in seed moisture and viability were monitored.

- Results B. ramiflora seeds are recalcitrant and highly sensitive to both high temperatures and dehydration, with a reduced lifespan when temperature increased or relative humidity decreased, and viability is lost when dehydrated to $0.198 \mathrm{~g} / \mathrm{g}$ or warmed to $\geq 35^{\circ} \mathrm{C}$. Germination was delayed in non-rainforest conditions compared with the rainforest understory, and only one-third of the seeds assigned to an open site germinated and emerged.
\end{abstract}

\section{Handling Editor: Erwin Dreyer}

Contribution of the co-authors The contribution of individual authors: Bin Wen designed the experiment, wrote the manuscript and supervised the work. Yifan Cai ran the experiment and analyzed the data.

B. Wen $(\bowtie)$

Key Laboratory of Tropical Forest Ecology, Xishuangbanna Tropical Botanical Garden, Chinese Academy of Sciences, Mengla,

Yunnan 666303, China

e-mail: wenb@xtbg.org.cn

Y. Cai

College of Agricultural and Biotechnology, China Agricultural

University, Beijing 100094, China
- Conclusion The results support our hypothesis that recalcitrant-seeded species have a high dependence on intact rainforests, and that fragmentation and disturbance will reduce their germination and establishment while favoring orthodoxseeded pioneers.

Keywords Desiccation tolerance · High-temperature stress · Microhabitat changes $\cdot$ Rainforest fragmentation $\cdot$ Species shift $\cdot$ Seedling establishment

\section{Introduction}

Southern Yunnan is on the north margin of the Asian tropics and is a hotspot for global biodiversity (Myers 1998), with the largest area of tropical rainforest remaining in China (Cao et al. 2006; Zhu 1997). Protecting this rainforest and its biota is a national conservation priority, but its marginal position latitudinally and climatically make it particularly vulnerable to disturbance (Zhu 2004). Unfortunately, the remaining rainforest has become seriously fragmented in recent decades because of the expansion of rubber and other cash crops (Li et al. 2009). Fragmentation results in edge effects, first changing the microclimate near the forest margins by increasing temperature and decreasing moisture, and subsequently changing the treecommunity composition, with pioneer and successional species increasing and large-seeded and old-growth taxa declining (Gascon et al. 2000; Laurance et al. 1998a, 1998b, 2006; Ma et al. 1998; Zhu et al. 2004). This may result in the extinction of some species endemic to tropical forests (Turner 1996; Zhu et al. 2010), but the mechanism for species shifts in fragmented rainforest is still not fully understood. We hypothesize that this shift in species composition 
originates, at least in part, from the different selection pressures on pioneer and climax seeds as the habitat changes, since these ecological species groups have different germination requirements, and seed germination and seedling establishment are the basis of forest dynamics. Swaine and Whitmore (1988) suggested that pioneer seeds germinate only in full sun, clearings or canopy gaps open to the sky, and require full sun for survival and growth, while climax seeds germinate in shade, or rarely in full sun, and seedlings can survive and grow in shade, although the difference between these seed groups is quantitative rather than qualitative and variation within them is continuous. We therefore expect that environmental changes in fragmented forests will stimulate germination of pioneer seeds and depress that of climax seeds.

Many climax species in tropical rainforests are known to produce recalcitrant seeds. Such seeds are sensitive to abiotic stresses (Roberts and King 1980; Tweddle et al. 2003), so it is necessary to assess their potential response to habitat fragmentation. Baccaurea ramiflora (Euphorbiaceae) is distributed widely in southern China and Southeast Asia. It is one of the most common species in Southern Yunnan tropical rainforests, with the third highest importance value in a 20 ha plot in the tropical seasonal rainforest in Xishuangbanna (3,212 individuals $\geq 1 \mathrm{~cm}$ diameter; Cao et al. 2008). Previous studies reported that $B$. ramiflora produces recalcitrant seeds (Yu et al. 2008). To assess the vulnerability of germination to fragmentation and edge effects, we tested whether habitat damage causes a decrease in germination of B. ramiflora seeds in the field, and whether increased temperature and decreased moisture truncate seed longevity in the laboratory.

\section{Materials and methods}

\subsection{Seed materials}

Mature fruits of B. ramiflora were collected in July 2011 from trees growing in the rainforest patch within the Xishuangbanna Tropical Botanical Garden (hereafter XTBG) (for climate see: Cao et al. 2006). Seeds were extracted and cleaned manually, and then kept in polyethylene bags at $15^{\circ} \mathrm{C}$ for a maximum of 3 days before use.

B. ramiflora seeds are flat-elliptic, arillate and endospermous, with a white or pinkish arillode. Inside the testa there is a tiny embryonic axis with two large, flat cotyledons, encapsulated by two fleshy endosperm pieces from each side. The seeds in this study had an initial germination percentage of $95.3 \pm 1.9 \%$ and $93.3 \pm 1.3 \%$, for seeds with a pinkish and white arillode, respectively. Their moisture contents were $1.54 \pm 0.09$ and $1.51 \pm 0.11 \mathrm{~g} / \mathrm{g}$ (dry weight basis), respectively, and their 100 -seed weights $32.96 \pm 0.26$ and $36.36 \pm 0.27 \mathrm{~g}$.

\subsection{Laboratory experiments}

Moisture contents, expressed as g water/g dry mass (g/g), were determined gravimetrically for eight individual seeds before and after drying for $17 \pm 1 \mathrm{~h}$ in a ventilated oven at $103 \pm 2{ }^{\circ} \mathrm{C}$. The response of germination to temperature was assessed by sowing fresh seeds in $1 \%$ distilled water agar in Petri dishes placed in constant temperatures of 10, 15, 20, 25, 30,35 , or $40{ }^{\circ} \mathrm{C}$ in temperature-controlled incubators, with $14 \mathrm{~h}$ light $\left(20 \mu \mathrm{mol} \mathrm{m}{ }^{-2} \mathrm{~s}^{-1}\right) / 10 \mathrm{~h}$ dark per day provided by white fluorescent tubes. Desiccation tolerance was assessed by placing seeds in a desiccator containing plenty of silica gel in an air-conditioned room at $20^{\circ} \mathrm{C}$. The seeds were placed on the surface of silica gel for up to $48 \mathrm{~h}$, with the silica gel renewed regularly, and sampled for moisture and viability determination at regular intervals. Seed viability assessment in this and the following experiments was carried out at $25 \pm$ $1{ }^{\circ} \mathrm{C}$ in light as described above.

The response of seeds to desiccation at different temperatures was assessed by a method used previously (Wen 2011). Seeds were placed in a monolayer in dishes put in incubators set at constant temperatures between 15 and $40{ }^{\circ} \mathrm{C}$. The relative humidity recorded in these incubators was $45-78 \%$ during the experiment. The response to desiccation under different relative humidities was assessed by exposing seeds in a monolayer in desiccators at relative humidities of $30 \%, 43 \%$, $62 \%, 75 \%, 93.6 \%$ and $100 \%$, regulated by saturated solutions of $\mathrm{CaCl}_{2}, \mathrm{~K}_{2} \mathrm{CO}_{3}, \mathrm{NH}_{4} \mathrm{NO}_{3}, \mathrm{NaCl}, \mathrm{KNO}_{3}$ and distilled water, respectively, at $25{ }^{\circ} \mathrm{C}$ in a temperaturecontrolled room. Seeds were sampled for moisture and viability determination regularly in both experiments.

\subsection{Field experiments}

Six $50 \mathrm{~cm} \times 50 \mathrm{~cm}$ quadrats (A-F) in five distinct habitats were chosen within XTBG. After removing covering plants and litter, approximately 1,200 seeds were placed in a monolayer on the ground in each quadrat, covered by a metal net to exclude seed predators, and sampled regularly for moisture and viability assessment until to the 10 days. Subsequently, germination of the seeds remaining in field was monitored once a week for 6 weeks. The quadrats and habitats were as follows:

Quadrats A and B: in a valley of the XTBG rainforest, altitude $562 \mathrm{~m}$, initial soil moisture content $38 \%$ (determined using surface soil sampled on the day the experiment was set up and expressed on a fresh weight basis), with a diverse plant cover and dense canopy; 
Quadrat C: on a slope in the XTBG rainforest, altitude $565 \mathrm{~m}$, soil moisture content $35 \%$, with a diverse plant cover and dense canopy;

Quadrat D: in a plantation of Mesua ferrea near the XTBG rainforest, altitude $570 \mathrm{~m}$, soil moisture content $23 \%$, with a dense canopy and dark, clean understory;

Quadrat E: in a pomelo orchard far away from the XTBG rainforest, altitude $580 \mathrm{~m}$, soil moisture content $20 \%$, with an open canopy and clean and clear understory;

Quadrat F: in a grassy area close to buildings, with direct sunlight between 10:00 a.m. and 16:00 p.m. on sunny days, soil moisture content $28 \%$.

\subsection{Seed germination test}

The germination test was performed for six Petri dishes containing 25 seeds each for each treatment. Seeds were incubated for at least 3 months and those that failed to germinate were then subjected to a crush test to confirm that they were nonviable. At least $1 \mathrm{~cm}$ radicle protrusion was considered as germination, while formation of a normal seedling was considered as emergence.

\subsection{Dehydration rate and desiccation tolerance assessment}

The seed moisture loss rate index (SMLRI) defined by Samarah et al. (2009) was modified to quantity the drying rate under different regimes by the following equation:

$S M L R I=\sum_{i=1}^{n}\left(S M C_{i}-S M C_{i+1}\right) / d a y_{i+1}$

where $\mathrm{SMC}_{\mathrm{i}}$ and $\mathrm{SMC}_{\mathrm{i}+1}$ are seed moisture contents (on a dry weight basis) of the sample numbers $i$ and $i+1$, and day ${ }_{i+1}$ is the number of days after imposing drying treatment for the sample number i+1. This differs from Samarah et al. (2009), who used moisture content expressed on a fresh weight basis. The units are $g$ water $g$ dry mass ${ }^{-1}$ day $^{-1}$.

Days for mid-point viability loss (T50) and the critical moisture content for $85 \%$ and $50 \%$ germination $\left(\mathrm{WC}_{85}\right.$ and $\mathrm{WC}_{50}$ ) were calculated by probit analysis.

\subsection{Statistical analyses}

Moisture contents on a dry weight basis were estimated as means $\pm \mathrm{SE}$ of eight replicates of single seeds. Seed germination was expressed as means $\pm \mathrm{SE}$ of six replicates of 25 seeds. Analysis of variance (ANOVA) was conducted on final germination percentages after arcsin transformation and a general linear model chosen. We applied one-way ANOVA to test whether incubation temperature and desiccation intensity influence seed germination separately, and two-way ANOVA to test whether desiccation regime, i.e., temperature, relative humidity or habitat in different experiment, and treatment time, and interaction of these two factors, influence seed germination, respectively. Data was processed using SPSS version 19 (SPSS, Chicago, IL).

\section{Results}

\subsection{Effects of temperature on seed germination}

Analysis of variance indicated that temperature significantly affected germination $(F=360, P<0.001)$ and emergence $(F=$ $385, P<0.001)$. B. ramiflora seeds had maximum emergence percentage when incubated at $30^{\circ} \mathrm{C}$ while maximum germination percentage was achieved at $20^{\circ} \mathrm{C}$, but neither emergence percentage nor germination percentage differ significantly between these two temperatures. No emergence was observed from seeds incubated at $10{ }^{\circ} \mathrm{C}$, or at $35^{\circ} \mathrm{C}$ or $40^{\circ} \mathrm{C}$. The same results were obtained for germination, except that $15 \%$ of seeds germinated at $10^{\circ} \mathrm{C}$ but failed to form seedlings (Fig. 1). Between 15 and $30^{\circ} \mathrm{C}$, the germination rate increased with temperature. One week after sowing, $23 \%$ seeds were found to have radicle protrusion at $30^{\circ} \mathrm{C}$, while this value was $12 \%$ for $25^{\circ} \mathrm{C}$ and $20^{\circ} \mathrm{C}$, and nil for $15^{\circ} \mathrm{C}$. Seeds incubated at $15^{\circ} \mathrm{C}$ to $30^{\circ} \mathrm{C}$ all finished root and shoot formation within $1-2$ months.

3.2 Desiccation tolerance of whole seeds under silica gel dehydration

B. ramiflora seeds lost moisture quickly under silica gel desiccation. This experiment lasted for only $48 \mathrm{~h}$, but seed moisture decreased from 1.54 to $0.066 \mathrm{~g} / \mathrm{g}$. The wide shoulder of the desiccation time-moisture course for recalcitrant seeds was not observed for B. ramiflora. However, B. ramiflora seeds are very sensitive to desiccation, which significantly influenced the germination $(F=78.1, P<0.001)$ and emergence $(F=76.2, P<0.001)$ percentages. Twenty-four hours dehydration depressed seed moisture to $0.198 \mathrm{~g} / \mathrm{g}$, with germination decreasing linearly with moisture content from $96 \%$ to zero. Probit analysis indicated that the critical moisture content is 1.38 and $0.818 \mathrm{~g} / \mathrm{g}$ for $85 \%$ and $50 \%$ seedling emergence, respectively. The percentage germination and emergence differed from each other only slightly in the 0.667 to $1.13 \mathrm{~g} / \mathrm{g}$ moisture range (Fig. 2). Overall, emergence was always closely linked with germination, with only slight differences $(<5 \%)$ detected, except for seeds incubated at 
Fig. 1 Germination and emergence percentages of Baccaurea ramiflora seeds incubated at $10-40{ }^{\circ} \mathrm{C}$ in temperature-controlled incubators. Values are expressed as means $\pm \mathrm{SE}$ of six replicates of 25 seeds

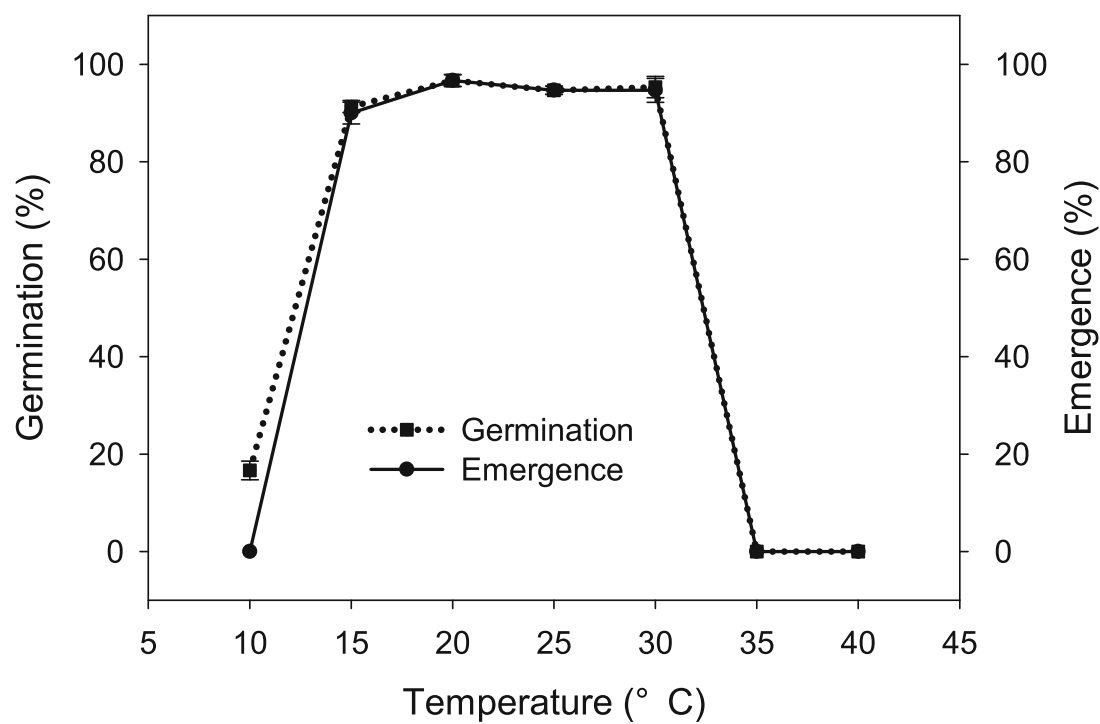

$10^{\circ} \mathrm{C}$ as mentioned above, so germination is not reported for the other experiments.

\subsection{Effects of temperatures on moisture content and viability} of whole seeds

As expected, temperature and treatment time both had a very significant influence on seed moisture $\left(F_{\text {temperature }}=\right.$ $38.8, F_{\text {time }}=22.3, P<0.001$ for both) and viability loss $\left(F_{\text {temperature }}=339, \quad F_{\text {time }}=465, \quad F_{\text {temperature } \times \text { time }}=38.4\right.$, $P<0.001$ for all). Among all the temperatures investigated, seeds subjected to $20{ }^{\circ} \mathrm{C}$ had the slowest moisture and viability loss rate, with SMLRI $=0.994 \mathrm{~g}$ $\mathrm{g}^{-1}$ day $^{-1}$ and $\mathrm{T} 50=3.5$ days. As the treatment temperature increased, the seeds lost moisture and viability more and more rapidly (Fig. 3). Seeds at $35{ }^{\circ} \mathrm{C}$ and
$40{ }^{\circ} \mathrm{C}$ behaved differently from those at lower temperatures, as at the higher temperature treatments equilibrium is reached quickly. Within the time period investigated, seeds at $15-30{ }^{\circ} \mathrm{C}$ lost moisture nearly linearly (Fig. 3a). Their emergence loss course had an obvious shoulder before they lost viability gradually, and these shoulders had almost the same width for the four temperatures (Fig. 3b). In contrast, temperatures of $35{ }^{\circ} \mathrm{C}$ and $40{ }^{\circ} \mathrm{C}$ depressed seed moisture to $0.25 \mathrm{~g} / \mathrm{g}$ within $24 \mathrm{~h}$, and these seeds reached their lowest values after 36 and $24 \mathrm{~h}$ (Fig. 3a), respectively, with T50s of only 0.64 and 0.35 days. From the co-plot between moisture content and emergence percentage, it can be seen that seeds at $40{ }^{\circ} \mathrm{C}$ lost most viability sharply at high moisture contents, so the curve had a convex slope; while those at $20{ }^{\circ} \mathrm{C}$ retained viability to lower moisture
Fig. 2 Viability loss of B. ramiflora seeds under dehydration by silica gel at $20^{\circ} \mathrm{C}$. Moisture contents are determined by eight replicates of single seeds; germination and emergence percentages are means $\pm \mathrm{SE}$ of six replicates of 25 seeds

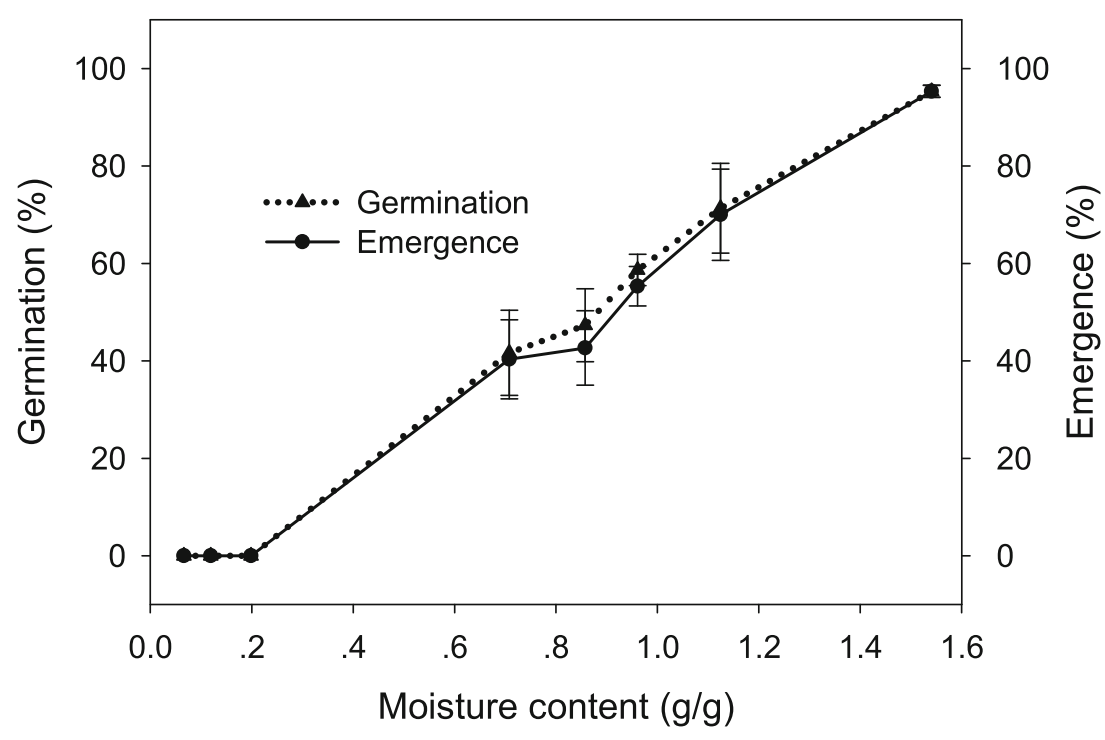



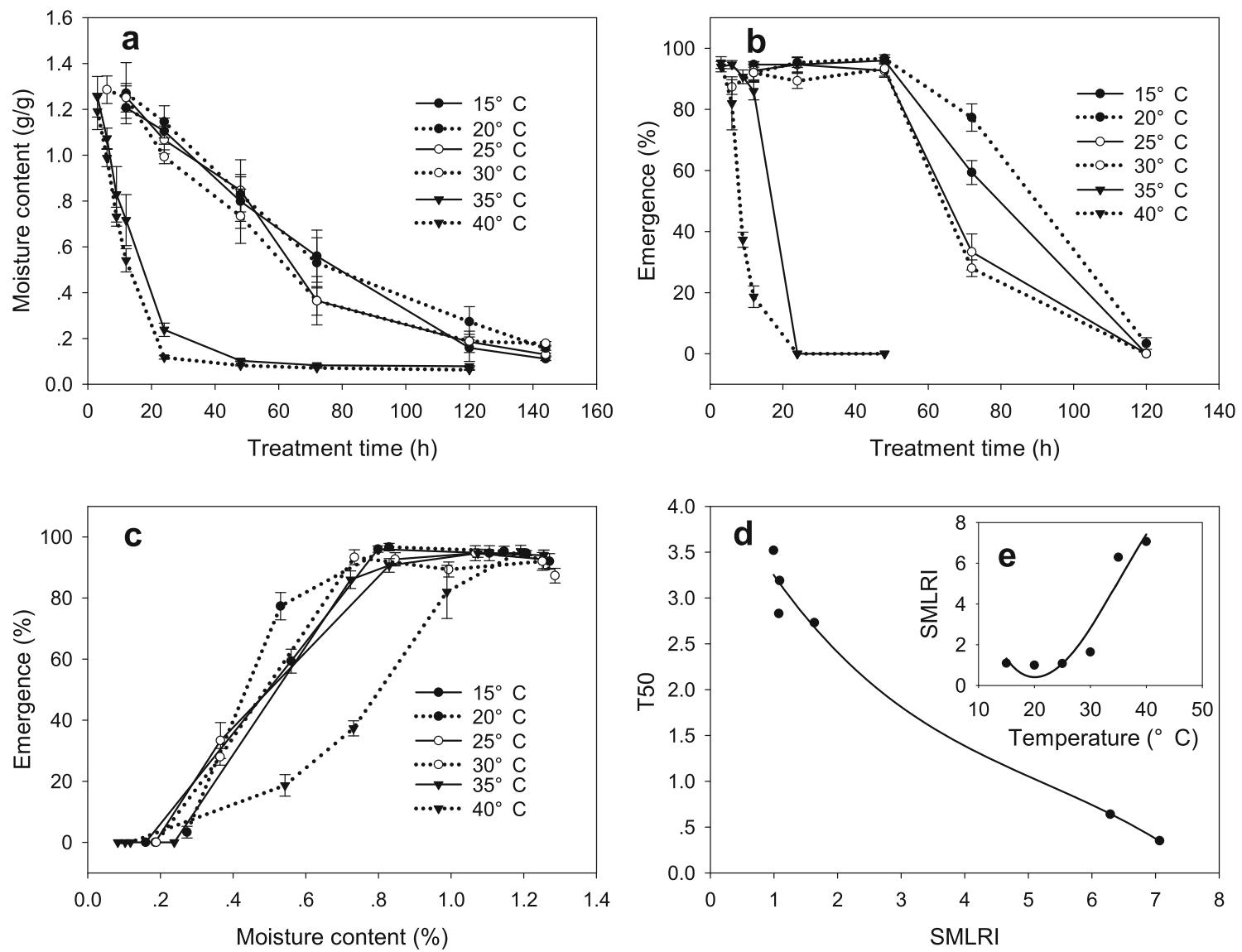

Fig. 3 a-e Moisture and viability loss of $B$. ramiflora seeds at different temperatures in temperature-controlled incubators. Moisture content expressed on a dry weight basis as means $\pm \mathrm{SE}$ of eight replicates of

single seeds. Emergence percentages as means \pm SE of six replicates of 25 seeds. The inset graph (e) shows the seed moisture loss rate index (SMLRI) co-plotted with temperature

and then lost their most viability sharply, so the curve had a concave slope (Fig. 3c).

There was a varying relationship between temperature and moisture loss, as SMLRI increased abruptly when seeds were subjected to $35^{\circ} \mathrm{C}$ and $40{ }^{\circ} \mathrm{C}$, while it increased gradually at temperatures between $15{ }^{\circ} \mathrm{C}$ and $30^{\circ} \mathrm{C}$ (Fig. 3e). Further, the drying rate provided a good explanation for variation in seed lifespan under different temperatures, as shown by T50 coplotted against SMLRI (Fig. 3d). However, we failed to find a relationship between moisture loss rate and critical moisture content (data not shown).

\subsection{Effects of relative humidity on moisture content} and viability of whole seeds

Relative humidity is another factor significantly influencing seed moisture $\left(F_{\mathrm{RH}}=6.33, P=0.001 ; F_{\text {time }}=\right.$ $11.8, P<0.001)$ and viability loss $\left(F_{\mathrm{RH}}=223, F_{\text {time }}=668\right.$, $F_{\mathrm{RH} \times \text { time }}=72.2, P<0.001$ for all). B. ramiflora seeds had an initial moisture content as high as $1.54 \mathrm{~g} / \mathrm{g}$ and seeds kept at RH $100 \%$ had a slight increase in moisture content in the course of experiment (Fig. 4a), with their viability staying essentially constant for up to 80 days

(Fig. 4b). Precocious germination was not observed, suggesting that an extra water supply is needed for germination and that wet storage could be used for short-term seed conservation. Seeds under RH 93.6\% lost moisture continuously (Fig. 4a) and exhausted viability over the course of the experiment (Fig. 4b). The lower the relative humidity, the faster the seeds lost moisture and the more rapidly they reached their equilibrium moisture content. Subsequently, they quickly lost their viability. From RH $93.6 \%$ to $30 \%$, every decline in relative humidity notably accelerated moisture loss (Fig. 4a), increased seed moisture loss rate (Fig. 4e) and curtailed seed lifespan (Fig. 4d). It was found that B. ramiflora seeds reached their equilibrium moisture content within 30 days when relative humidity fell below $60 \%$ (Fig. 4a). T50 was 22.1, 16.8, 10.4, and 2.24 days for seeds under RH $75 \%, 62 \%, 43 \%$ and $30 \%$, respectively (Fig. 4d). Seeds at low relative humidity had short longevity as they lost both viability and moisture content rapidly, while those at high relative humidity had long longevity as they retained viability and moisture longer, and then lost viability sharply at a higher moisture content (Fig. 4c). 
Drying rate is an important cause for variation in seed lifespan under different relative humidities (Fig. 4d), and relative humidity provided a partial explanation for SMLRI (Fig. 4e).

\subsection{Changes in seed moisture and viability in the field}

Both habitat and treatment time had significant effects on seed viability $\left(F_{\text {habitat }}=62.5, P<0.001 ; F_{\text {time }}=2.66\right.$, $\left.P=0.035 ; F_{\text {habitat } \times \text { time }}=5.14, P<0.001\right)$, but only habitat on seed moisture $\left(F_{\text {habitat }}=32.5, P<0.001 ; F_{\text {time }}=1.38\right.$, $P=0.277$ ). A one-day treatment made the moisture content of seeds assigned to Quadrat F significantly lower than those assigned to Quadrats A-E, and it decreased further after 2 days. Although seed moisture rose again after a thunderstorm in the following days, these seeds had lower moisture content in the whole experiment (Fig. 5a). In accordance with this, seed emergence from Quadrat $\mathrm{F}$ decreased rapidly to $30 \%$ (Fig. 5b).

Although seeds from Quadrats D and E had almost as high moisture (Fig. 5a) and viability (Fig. 5b) as those from
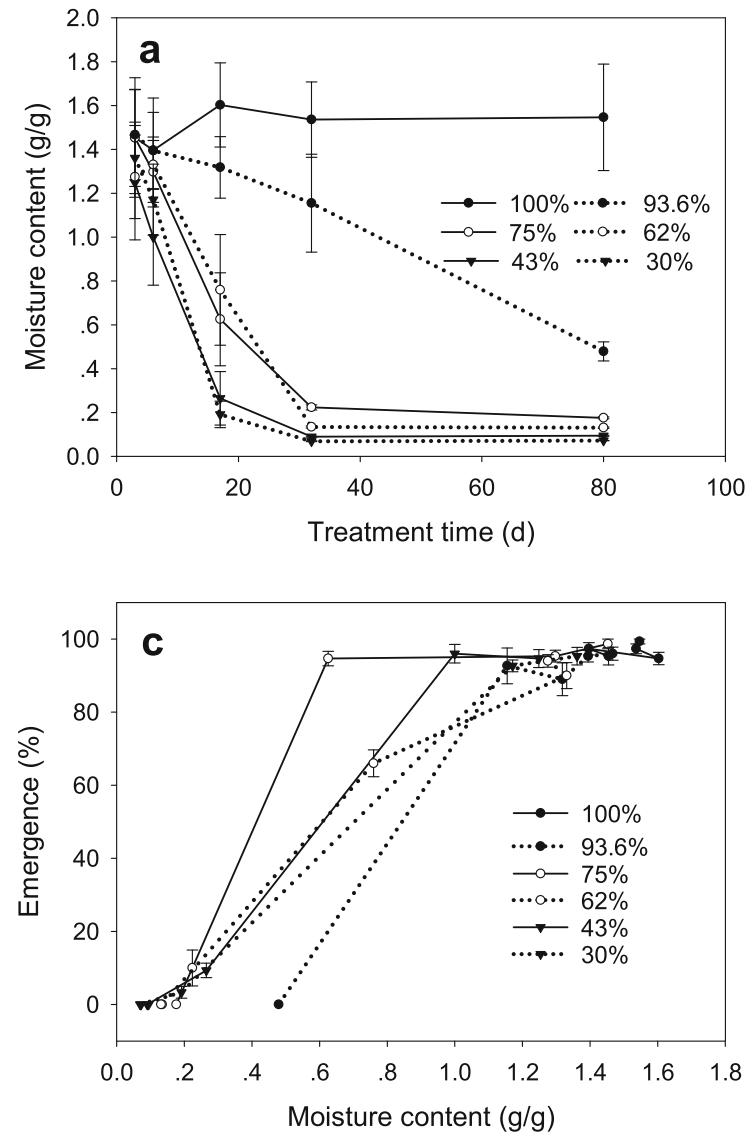

Fig. 4 a-e Moisture and viability loss of $B$. ramiflora seeds at different relative humidities regulated by saturated solutions of $\mathrm{CaCl}_{2}, \mathrm{~K}_{2} \mathrm{CO}_{3}$, $\mathrm{NH}_{4} \mathrm{NO}_{3}, \mathrm{NaCl}, \mathrm{KNO}_{3}$ and distilled water, in desiccators at $25{ }^{\circ} \mathrm{C}$. Moisture contents are expressed on a dry weight basis as means $\pm \mathrm{SE}$
Quadrats A-C, they behaved differently in the field. Six days after they were assigned to habitats, more than $60 \%$ of seeds in Quadrats A and B had germinated in the field, but only $30 \%$ and $13 \%$ in Quadrats C and D, and none in Quadrats E and $\mathrm{F}$. By the 10 days, more than $95 \%$ of seeds in Quadrats A-C had germinated, with 5-cm long roots, while 20 days were needed for seeds to reach this germination stage in Quadrats D and E. One month later, almost all seeds had formed normal seedlings in the field except that emergence was only $35 \%$ for Quadrat F.

\section{Discussion}

This study confirmed previous reports that $B$. ramiflora produces recalcitrant seeds (Yu et al. 2008). Under silica gel desiccation, they lost viability within $24 \mathrm{~h}$ as moisture content decreased from 1.54 to $0.198 \mathrm{~g} / \mathrm{g}$. Using graded temperatures and relative humidity to mimic the changed microclimate in rainforest fragments, this study showed that both increases in
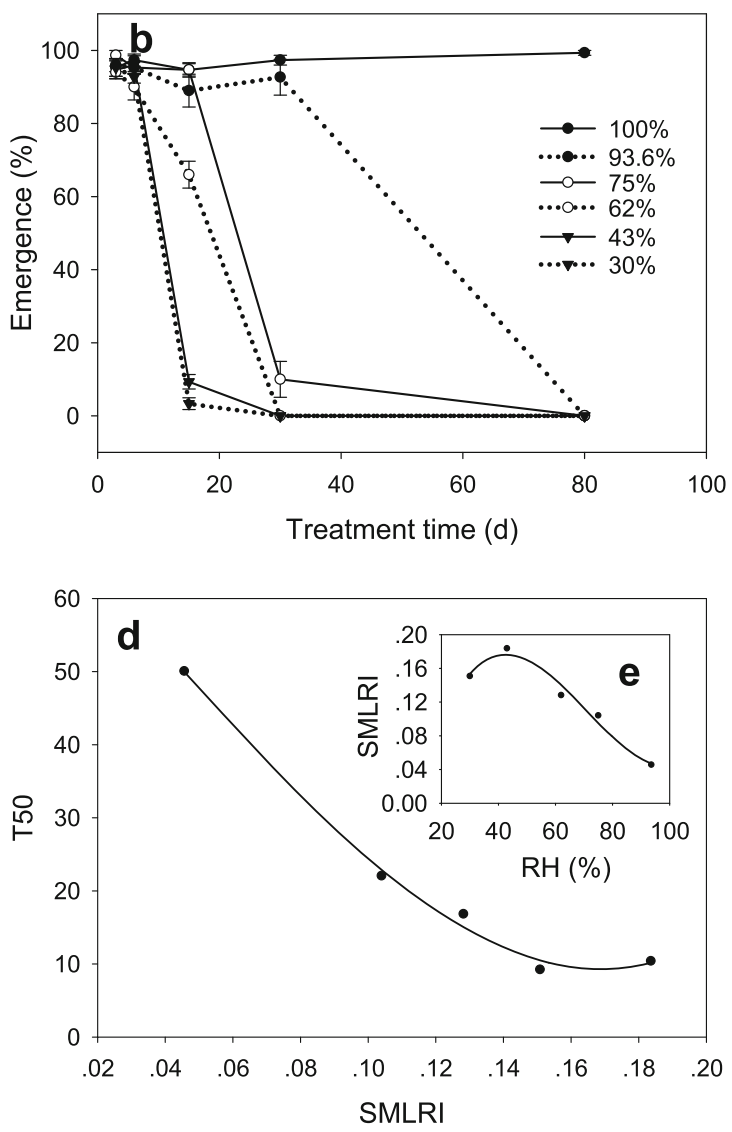

of eight replicates of single seeds; emergence percentages are means $\pm \mathrm{SE}$ of six replicates of 25 seeds. The inset graph (e) shows the SMLRI coplotted with relative humidity (RH $100 \%$ not included as there was no moisture loss under this regime) 


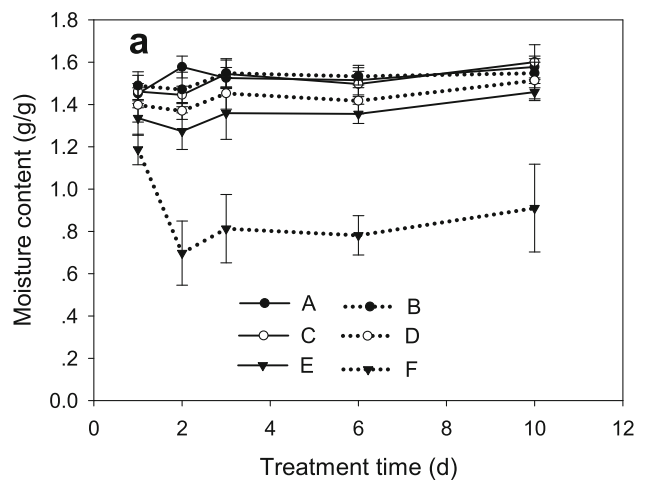

Fig. 5 a Moisture and b viability loss of B. ramiflora seeds placed on the soil surface in different habitats. Seeds were sampled from the field for viability and moisture determination. Quadrat $A$ and $B$ are in a rainforest valley, Quadrat $C$ is on a slope in the same rainforest, Quadrat $D$ is in an artificial forest of Mesua ferrea near the rainforest, Quadrat $E$ is in a

temperature and decreases in relative humidity accelerate loss of moisture and viability, although the response patterns were complex. B. ramiflora seeds had a higher initial moisture content than the Hopea mollissima seeds studied previously (Wen 2011) (1.54 vs $0.667 \mathrm{~g} / \mathrm{g}$ ), but we did not observe precocious germination under RH $100 \%$ as occurred with Hopea mollissima, although both had an increase in moisture under this humidity.

Because of its wide distribution and high importance value (Cao et al. 2008), B. ramiflora is a critical species in Xishuangbanna tropical rainforests, as well as being representative of other climax species with recalcitrant seeds. B. ramiflora sheds seeds in the rainy season, and can complete germination within 10 days in the rainforest. In contrast, they lost moisture and viability rapidly when subject to drying, with a high critical moisture content. Almost all seeds germinated in the intact rainforest (Quadrats A-C), while in artificial forests (Quadrats D and E) germination was delayed. B. ramiflora seeds have been reported previously to have a high germination percentage in both the forest understory and in a canopy gap (Yu et al. 2008), but in this study two-thirds of the seeds failed to germinate in the non-forest habitat (Quadrat F), which is more open than the gap in the previous study.

Tropical recalcitrant seeds often initiate germination on the parent plants or shortly after release, so species with such seeds persist as an understory seedling bank rather than a soil seed bank (Dickie and Pritchard 2002; Farnsworth 2000; Thompson 2000; Vázquez-Yanes et al. 2000). In this study, $B$. ramiflora seeds had high final emergence in understory conditions, both in closed rainforest and artificial forests. Generally, recalcitrant seeds are spherical/ovoid while seeds of this species are flat. The seeds are also rather small compared to most typical recalcitrant seeds, such as mango and chestnut, with 100 -seed weight of $30 \mathrm{~g}$ vs $>100 \mathrm{~g}$. This is likely to mean less resistance to desiccation, as small and flat seeds lose moisture more quickly under dry conditions, in

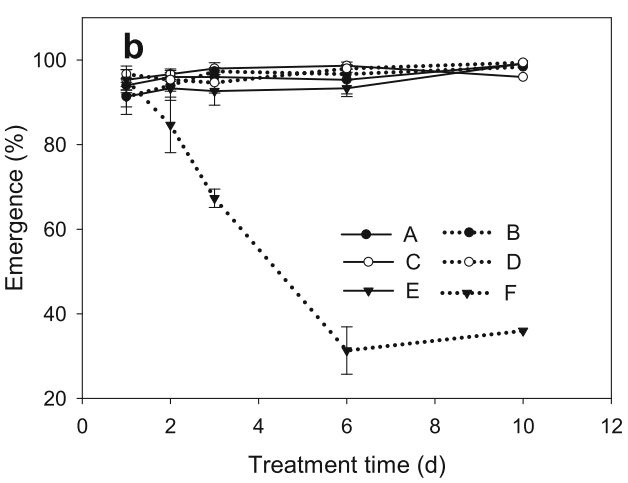

pomelo orchard far away from the rainforest, and Quadrat $F$ is in grassland close to buildings where sunlight can reach directly between 10:00 a.m. and 4:00 p.m. on sunny days. Moisture contents are expressed on a dry weight basis as means $\pm \mathrm{SE}$ of eight replicates of single seeds; emergence percentages are means \pm SE of six replicates of 25 seeds

addition to limited food reserves for germination and establishment at low levels of solar radiation.

Rainforest fragmentation results in both microclimate changes and changes in species composition. Though the relationship between them is likely to be complex, microclimate changes may influence germination, as shown by Bruna (1999), and thus lead to changes in species composition. Accumulated evidence from ecological studies supports this inference, although studies of the effects of fragmentation on seed germination are limited. For example, by investigating the germination of 43 tree species native to the lowland forests of Malaysia in three different habitats, Raich and Khoon (1990) found that most forest canopy species germinated in the gap, but germination in the large clearing was reduced dramatically. Conversely, canopy-induced inhibition of germination was apparent in pioneer species. They concluded that germination requirements play a very important role in controlling the species composition of regeneration in forest understorey, gap, and large clearing habitats (Raich and Khoon 1990). Many other studies, such as those of Kyereh et al. (1999), Vásquez-Yanes and Orozco-Segovia (1990), Metcalfe (2001), Souza and Válio (2001), Daws et al. (2002), and Chen et al. (2013), covering both field and/or laboratory work, have reported differences in seed germination response of pioneer and non-pioneer species. These studies show that forest fragmentation will favor the germination and seedling establishment of pioneer species because this will cause increased sunlight and temperature fluctuations, in the same way as gap formation, but why and how the microclimate changes in fragmented rainforests reduces germination and truncates the longevity of climax seed species is still not fully understood, in part because of the difficulty in assessing the effects of multiple, changing, factors under field conditions. Wen (2011) studied the effects of increased temperature and decreased relative humidity on moisture content and viability of Hopea mollissima seeds using graded temperatures and 
relative humidity. B. ramiflora seeds are similar to H. mollissima seeds in that they exhibit high sensitivity to changes in temperature and relative humidity, but differ in that they lose moisture and viability more rapidly when subjected to high temperature and low RH. Both of these seed species need forest habitats to germinate in the field.

Seeds at the open site were subject to high temperatures as well as low humidity. Although high temperatures accelerate seed moisture loss (Fig. 3a), these seeds lost viability at relatively higher moisture contents (Fig. 3c), implying that high temperature itself is lethal to B. ramiflora seeds, as was also shown under the experimental temperature treatments. Ground temperatures in forest gaps in Xishuangbanna can reach $>40{ }^{\circ} \mathrm{C}$ (Liu et al. 2000), suggesting that the thermal tolerance of rainforest seeds deserves further study.

In conclusion, $B$. ramiflora seeds are very sensitive to dehydration and high temperatures and require rainforest habitats for germination. Fragmentation and deforestation will impair germination and make seedling establishment a bottleneck in the plant life cycle. The vulnerability of recalcitrant seeds to high temperatures needs further investigation. In fragmented tropical rainforests, species like $B$. ramiflora producing recalcitrant seeds have more difficulties than those producing orthodox seeds, thus favoring pioneers over climax species. Rainforest conservation managers need to pay more attention to the germination and establishment of species with recalcitrant seeds. To prevent extinction of recalcitrant-seeded climax species from tropical rainforests, management should focus on maintaining interior forest conditions.

Acknowledgment We are grateful to Prof. Richard Corlett in our botanical garden for providing linguistic help. Thanks are given to the National Natural Science Foundation of China (31170626) for providing financial support for this research.

\section{References}

Bruna EM (1999) Seed germination in rainforest fragments. Nature 402: 139

Cao M, Zou XM, Warren M, Zhu H (2006) Tropical forests of Xishuangbanna, China. Biotropica 38:306-309

Cao M, Zhu H, Wang H, Lan GY, Hu YH, Zhou SS, Deng XB, Cui JY (2008) Xishuangbanna tropical seasonal rainforest dynamics plot: tree distribution maps, diameter tables and species documentation. Yunnan Science and Technology Press, Kunming

Chen H, Cao M, Baskin JM, Baskin CC (2013) Temperature regulates posivively photoblastic seed germination in four Ficus (Moraceae) tree species from contrasting habitats in a seasonal tropical rainforest. Am J Bot 100:1683-1687

Daws MI, Burslem DFRP, Crabtree LM, Kirkman P, Mullins CE, Dalling JW (2002) Differences in seed germination responses may promote coexistence of four sympatric piper species. Funct Ecol 16:258-267

Dickie JB, Pritchard HW (2002) Systematic and evolutionary aspects of desiccation tolerance in seeds. In: Black M, Pritchard HW (eds) Desiccation and survival in plants: drying without dying. CAB International, Wallingford, pp 239-259
Farnsworth E (2000) The ecology and physiology of viviparous and recalcitrant seeds. Annu Rev Ecol Evol Syst 31:107-138

Gascon C, Williamson GB, da Fonseca GAB (2000) Receding forest edges and vanishing reserves. Science 288:1356-1358

Kyereh B, Swaine MD, Thompson J (1999) Effect of light on the germination of forest trees in Ghana. J Ecol 87:772-783

Laurance WF, Ferreira LV, Merona JMR, Laurance SG (1998a) Rain forest fragmentation and the dynamics of Amazonian tree communities. Ecology 79:2032-2040

Laurance WF, Ferreira LV, Merona JMR, Laurance SG, Hutchings RW, Lovejoy TE (1998b) Effects of forest fragmentation on recruitment pattern in Amazonian tree communities. Conserv Biol 12:460-465

Laurance WF, Nascimento HEM, Laurance SG, Andrade A, Ribeiro JLS, Giraldo JP, Lovejoy TE, Condit RC, Chave J, Harms KE, D'Angelo $S$ (2006) Rapid decay of tree-community composition in Amazonian forest fragments. Proc Natl Acad Sci USA 103: 19010-19014

Li HM, Ma YX, Liu WJ, Liu WJ (2009) Clearance and fragmentation of tropical rain forest In Xishuangbanna, Sw, China. Biodivers Conserv 18:3421-3440

Liu WJ, Li QJ, Zhang GM, Shi JP, Bai KJ (2000) Microclimatic characteristics of canopy gaps in Shorea chinensis forest in Xishuangbanna (in Chinese with English abstract). Acta Phytoecologica Sinica 24: 356-361

Ma YX, Liu YH, Zhang KY (1998) On microclimate edge effects of tropical rainforest fragments in Xishuangbanna (in Chinese with English abstract). Acta Phytoecologica Sinica 22:250-255

Metcalfe DJ (2001) Germination of small-seeded tropical rain forest plants exposed to different spectral compositions. Can J Bot 74: $516-520$

Myers N (1998) Threatened biotas: "hotspot" in tropical forests. Environmentalist 8:1-20

Raich JW, Khoon GW (1990) Effect of canopy openings on tree seed germination in a Malaysian dipterocarp forest. J Trop Ecol 6: 203-217

Roberts EH, King MW (1980) The characteristics of recalcitrant seeds. In: Chin HF, Roberts EH (eds) Recalcitrant crop seeds. Tropical, Kuala Lumpur, pp 1-5

Samarah NH, Mullen RE, Alqudah AM (2009) An index to quanitify seed moisture loss rate in relationship with seed desiccation tolerance in common vetch. Seed Sci Technol 37: 413-422

Souza RP, Válio IFM (2001) Seed size, seed germination, and seedling survival of Brazilian tropical tree species differing in successional status. Biotropica 33:447-457

Swaine MD, Whitmore TC (1988) On the definition of ecological species groups in tropical rain forests. Vegetatio 75:81-86

Thompson K (2000) The functional ecology of soil seed banks. In: Fenner $M$ (ed) Seeds: the ecology of regeneration in plant communities, 2nd edn. CAB International, Oxford, pp 215-235

Turner IM (1996) Species loss in fragments of tropical rain forest: a review of the evidence. J Appl Ecol 33:200-209

Tweddle JC, Dickie JB, Baskin CC, Baskin JM (2003) Ecological aspects of seed desiccation sensitivity. J Ecol 91:294-304

Vásquez-Yanes C, Orozco-Segovia A (1990) Ecological significance of light-controlled seed germination in two contrasting tropical habitats. Oecologia 83:171-175

Vázquez-Yanes C, Orozco-Segovia A, Sánchez-Coronado ME, Rojas-Aréchiga M, Batis AI (2000) Seed ecology at the northern limit of the tropical rain forest in America. In: Black M, Bradford KJ, Vazquez-Ramos J (eds) Seed biology: advances and applications. CAB International, Wallingford, UK, pp 375-388 
Wen B (2011) Changes in the moisture and germination of recalcitrant Hopea mollissima seeds (Dipterocarpaceae) in different desiccation regimes. Seed Sci Technol 39:214-218

Yu Y, Baskin JM, Baskin CC, Tang Y, Cao M (2008) Ecology of seed germination of eight non-pioneer tree species from a tropical seasonal rain forest in Southwest China. Plant Ecol 197:1-16

Zhu H (1997) Ecological and biogeographical studies on the tropical rain rorest of South Yunnan, Sw China with a special reference to its relation with rain forests of tropical Asia. J Biogeogr 24:647-662
Zhu H (2004) A tropical seasonal rain forest at its altitudinal and latitudinal limits in Southern Yunnan, Sw China. Gardens' Bulletin (Singapore) 56:55-72

Zhu H, Xu ZF, Wang H, Li BG (2004) Tropical rain forest fragmentation and its ecological and species diversity changes in Southern Yunnan. Biodivers Conserv 13:1355-1372

Zhu H, Wang H, Zhou SS (2010) Species diversity, floristic composition and physiognomy changes in a rainforest remnant in Southern Yunnan, China after 48 years. J Trop For Sci 22:49-66 